\title{
Article \\ An Approach to Determine the Median Diameter of Droplets in a Water-Mist Spray
}

\author{
H. M. Iqbal Mahmud ${ }^{1,2}, * \mathbb{0}$, Graham Thorpe ${ }^{2}$ and Khalid A. M. Moinuddin ${ }^{2}(\mathbb{D}$ \\ 1 Department of Civil Engineering, Khulna University of Engineering \& Technology, Khulna 9203, Bangladesh \\ 2 Institute of Sustainable Industries and Liveable Cities, Victoria University, P.O. Box 14428, \\ Melbourne, VIC 8001, Australia; graham.thorpe@vu.edu.au (G.T.); khalid.moinuddin@vu.edu.au (K.A.M.M.) \\ * Correspondence: iqbal.mahmud@ce.kuet.ac.bd
}

Citation: Mahmud, H.M.I.;

Thorpe, G.; Moinuddin, K.A.M. An

Approach to Determine the Median

Diameter of Droplets in a Water-Mist Spray. Appl. Sci. 2022, 12, 1073. https: //doi.org/10.3390/app12031073

Academic Editor: Jacek Tomków

Received: 22 September 2021

Accepted: 12 January 2022

Published: 20 January 2022

Publisher's Note: MDPI stays neutral with regard to jurisdictional claims in published maps and institutional affiliations.

Copyright: () 2022 by the authors Licensee MDPI, Basel, Switzerland. This article is an open access article distributed under the terms and conditions of the Creative Commons Attribution (CC BY) license (https:/ / creativecommons.org/licenses/by/ $4.0 /)$.

\begin{abstract}
The physical characteristics of water sprays profoundly influence the efficacy with which fires are extinguished. One of the most important physical characteristics of water sprays is the median diameter of the water droplets. However, this parameter is difficult to measure without resorting to the use of specialised equipment. Furthermore, the distribution of the size of water droplets and their initial velocity are profoundly sensitive to the pressure at the nozzle head. This paper presents a simple technique to determine the median droplet size of a water spray produced by a nozzle. The method required only two experiments to determine the mass flux distribution generated by a nozzle operating at two known pressures. A computational fluid dynamics (CFD) program was then used to estimate the median diameter of the water spray under these conditions. The median droplets generated when the nozzle was operating under a different pressure can be calculated using an established empirical relationship. The approach advocated in this paper is supported by invoking Whewell's principle of consilience of inductions. This was achieved by observing that the CFD software accurately predicts the mass flux distribution when the new pressure and estimated median diameter of the droplets were used as inputs. This provides independent evidence that the proposed approach has some merit. The findings of this research may contribute to establish a technique in calculating the median diameter of droplets when direct measurement of droplet diameter is not available.
\end{abstract}

Keywords: water-mist; droplet diameter; computational fluid dynamics; flux density distribution; FDS

\section{Introduction}

Water-mist fire suppression systems (WMFSS) represent a promising technology for various applications within the field of fire protection due to their low demand for water and their highly effective fire suppression capability [1]. The water-mist spray comprises fine mists with a higher surface area/volume ratio, resulting in rapid evaporation [2]. However, the efficacy of water-mist sprays in suppressing fires is strongly influenced by the characteristics of the sprays [3,4]. These characteristics are ultimately governed by the initial spray parameters [5]. One of the most important of them is the initial droplet size. Particularly, drop-size distribution and characteristic diameter (volume mean diameter or median diameter) of the spray yield to a clear representation of the atomisation degree [6,7].

The median droplet size of a spray can be determined experimentally using one of the several laser-based methods that are available. Numerous research studies have been performed to investigate the characteristics diameter of spray, including other parameters such as droplet size distribution, volumetric mean diameter (VMD), spray pattern, coverage area and so on for sprinkler and water-mist nozzle. Some of the early research was conducted on the water density and drop size distribution of the early suppression fast response ESFR sprinkler by Yao [8], Yu and Symonds [9], Yu [10] and Chen [11]. Montero et al. [12] performed experiments to measure droplet size distribution produced by a sprinkler using 
an optical spectropluviometer. They also investigated the effect of working pressure and nozzle size on the size distribution of droplets. Dwomoh et al. [13] conducted experiments to gain information about its droplet size distribution in the wind, using the laser precipitation monitor. Santangelo [7] conducted a study to investigate the characteristics of a water-mist spray produced by a typical atomiser at high operative pressure (in the range $60-80$ bar). They used laser-diffraction-based instruments to evaluate drop size, and particle image velocimetry (PIV) technique to determine the spray's velocity field and spray-cone angle. The specialised techniques for determining spray characteristics are also reported by Wang et al., 2008 [14], which generate data on the multiple scattering attenuation of light in dense sprays of water-mist. The first concern is that these laser-based methods are very expensive and require specialised techniques. The second concern is that the size distribution of water droplets and their initial velocity are susceptible to the pressure at the nozzle head [15]. Therefore, with regard to experimental studies, the drop size of sprays has represented a challenge for decades as a parameter to be quantitatively determined [7]. Furthermore, research in the domain of water spray systems remains important due to the complexity involved in predicting the interaction between the water sprays and the fire environment [15].

In recent years, computational fluid dynamics (CFD) models have been increasingly used to investigate the growth and suppression of fires, including the dynamics of sprays [3]. There can be an alternative way to use a CFD-based model to determine the spray parameters of a water mist nozzle. The median diameter (VMD) of droplets is one of the spray parameters used to define the spray characteristics. Therefore, this paper suggests a relatively simple technique for determining the median droplet size from a nozzle spray. This technique requires only two simple experiments to determine the mass flux distribution generated by a spray nozzle operating at two known pressures and a CFD model to estimate the median diameter of the water spray under these conditions. In this work, a Fire Dynamic Simulator (FDS) is used to simulate the spray. FDS is a widely used open-source CFD model, which is used to simulate the spread and suppression of fires in buildings [16-21]. The capability of a FDS in predicting the spray dynamics [16-20] and distribution of volume flux density of water droplets [3] was also validated in the previous studies.

The findings of this research may contribute to establishing a technique in calculating the median diameter of droplets when direct measurement of droplet size is not attainable. Furthermore, most of the CFD-based model uses the median size of droplets as the characteristic diameter of a spray, which represents the degree of atomisation of the spray $[7,15]$. Therefore, the outcome of this study can be used as the input parameter for the numerical tools for modelling the fire and water-mist interaction. This study will also be useful in agricultural irrigation, energy, transport and many other industrial technologies where water spray atomisation is essential.

\section{Methodology}

Firstly, an experiment was conducted where a water-mist nozzle was operated at a particular pressure $\left(P_{1}\right)$. The water of the spray was collected on a set of water collection trays on the floor. The distribution of flux density of water droplets produced by a watermist nozzle was quantified for the particular flow pressure $\left(P_{1}\right)$ in the experiment. The flow rate of water and the angle of the spray was also measured in the experiment. After that, a numerical tool, FDS, was used to simulate the experiment. A number of simulations were performed with a range of droplet sizes, and the distribution of flux density of water droplets for each size of droplet was calculated. Subsequently, the numerical results were compared with the experimental data. When the numerical distribution data were matched with the experimental data, the corresponding droplet size could be taken as the hypothetical median size of droplets $\left(d m_{1}\right)$ of the spray. This droplet size was considered to correspond to reality. Therefore, it was proposed that a mathematical relationship could be used to determine the second median diameter of droplets $\left(d m_{2}\right)$ for a different flow pressure $\left(P_{2}\right)$. If the numerical tool can accurately simulate the second set of flux distribution 
of water droplets using $d m_{2}$ and $P_{2}$, then we can be confident that the numerical tool is well-validated. Therefore, $d m_{1}$ and $d m_{2}$ can be considered as the actual droplet sizes of sprays corresponding to the $P_{1}$ and $P_{2}$, respectively.

According to Fleming [22], the median droplet diameter of a spray has been empirically found to be inversely proportional to the one-third power of water pressure and directly proportional to the two-third power of the diameter of the nozzle orifice, i.e.,

$$
d_{m} \propto \frac{D^{2 / 3}}{P^{1 / 3}} .
$$

Here $d m$ is the median size of droplets, $D$ is the diameter of the orifice and $P$ is the pressure of the water flow. Hence, for a particular nozzle, the correlation between the two median diameters of droplets corresponding to the two different pressures can be expressed as

$$
\frac{d_{m 1}}{d_{m 2}}=\left(\frac{P_{2}}{P_{1}}\right)^{1 / 3}
$$

The water flow pressure $\left(P_{1}\right)$ had already been determined in the first experiment. The corresponding median diameter of droplets $\left(d m_{1}\right)$ was determined from the same experiment and a set of simulations using the data of flux density distribution of water droplets. A second experiment was conducted with a different flow pressure $\left(P_{2}\right)$, and the corresponding data of the distribution of flux density of water spray was collected. Using Equation (2), the median diameter of droplets $\left(d m_{2}\right)$ of the spray was calculated for $P_{2}$. The flow rate of water and the angle of the spray was also measured in the experiment. Finally, this droplet size, the corresponding pressure, and other spray parameters were used as input parameters for the spray in the numerical model. If the numerical distribution of flux density of water matches the experimental measurements, we can conclude that the numerical model can predict the distribution of flux density of water droplets. We can be confident that hypothetical median droplet sizes $d m_{1}$ and $d m_{2}$ are the actual median droplet diameters at pressures $P_{1}$ and $P_{2}$, respectively. Therefore, we can estimate the median droplet diameters corresponding to different flow pressures using this method. The execution of this methodology is presented in detail in the following sections.

\section{Experimental Setup}

An experimental rig was fabricated to quantify the flux density distribution of the spray emanated from a nozzle. The setup of the test rig is shown in Figure 1. A single orifice water-mist nozzle was used to produce the spray. The diameter of the orifice was $1.524 \mathrm{~mm}$. The nozzle's orifice is positioned at the centre in the body of the nozzle and discharges an axisymmetric spray around the nozzle axis. A schematic of the single-orifice nozzle used in the experiment is presented in Figure 2. A pump with a capacity of 400 bars was used to supply water from a water reservoir to the nozzle. A water collection tray of $2 \mathrm{~m} \times 2 \mathrm{~m} \times 0.1 \mathrm{~m}$ in size was positioned on the floor to collect the water from the spray. The nozzle head was placed $2.3 \mathrm{~m}$ above the floor, and the centre of the water collection tray was directly underneath the nozzle head. The tray was divided into 400 boxes, and the dimension of each box was $10 \mathrm{~cm} \times 10 \mathrm{~cm} \times 10 \mathrm{~cm}$. The pump was operated to produce the spray at the end of the nozzle, and the collection of water was delayed until a stable spray was observed. The water of the spray was collected on the tray for $180 \mathrm{~s}$, and the accumulation of water in the boxes was measured. The distribution of flux density of the spray on the tray was expressed in terms of $\mathrm{L} / \mathrm{m}^{2} / \mathrm{min}$.

The angle of the spray was measured from the photographs of the experiment. It was performed by taking a photograph of the spray during the experiment. Afterwards, the angle of the spray was determined by processing the image. A photograph of the spray and a schematic of the measurement technique of the angle of spray are presented in Figure 2. The parameters of the angle of spray, the height of spray, and the water flow rate of the experiments were used as input in the FDS simulation. 


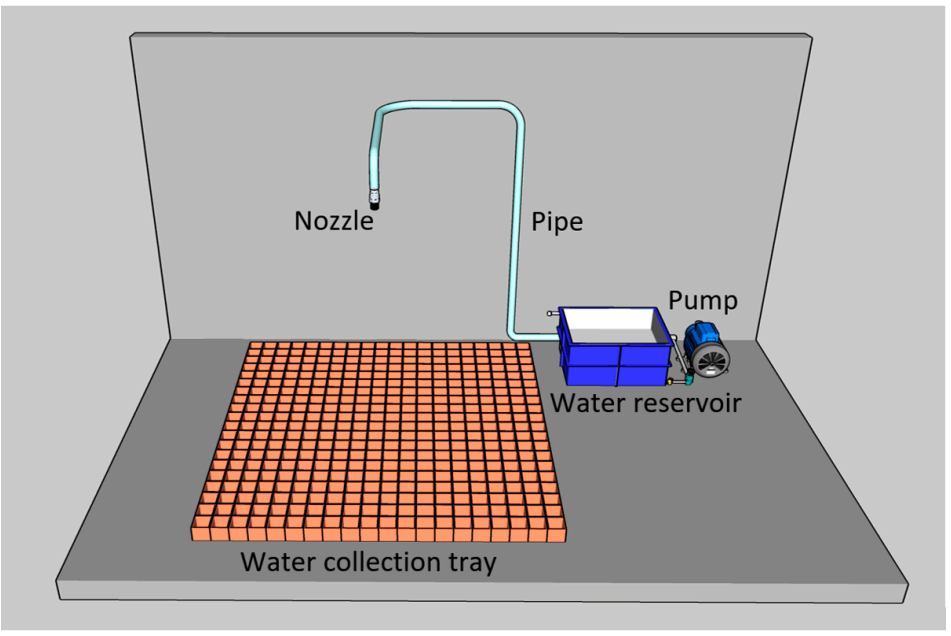

Figure 1. Schematic of the setup of the experiment.

(a)

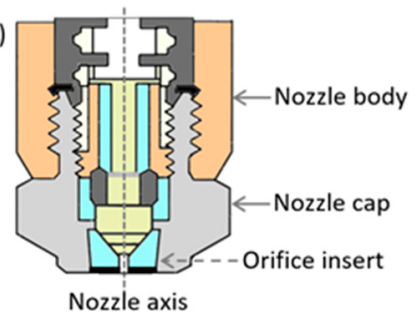

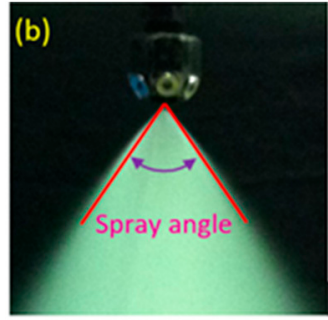

Figure 2. Spray nozzle and measurement of the angle of spray produced by the nozzle: (a) schematic of the single-orifice nozzle, (b) photograph of the spray, (c) schematic of measurement of the spray angle.

\section{Numerical Model}

Fire Dynamic Simulator (FDS), version 6, was used for the numerical modelling of the spray distribution, and the accompanying programme, Smokeview, was used to visualise the model. In FDS, a finite difference technique was applied to solve partial differential equations of conservation of mass, momentum and energy.

FDS takes a sample of spherical droplets to calculate the distribution pattern. The droplet size distribution is expressed in terms of its cumulative volume fraction $(C V F)$, which is represented by a combination of log-normal and Rosin-Rammler distributions [23].

$$
F(d)=\left\{\begin{array}{cc}
(2 \pi)^{-\frac{1}{2}} \int_{0}^{D_{C V F}}(\sigma D)^{-1} e^{\frac{\left[\ln \left(\frac{D}{D_{m}}\right)\right]^{2}}{2 \sigma^{2}}} d D & \left(D_{C V F} \leq D_{m}\right) \\
1-e^{-0.693\left(D_{C V F} / D_{m}\right)^{\gamma}} & \left(D_{C V F}>D_{m}\right)
\end{array}\right.
$$

where $D$ is the generic droplet diameter and $D_{m}$ is the median droplet diameter. The median droplet diameter is a function of the sprinkler/nozzle orifice diameter, operating pressure and geometry. $\gamma$ and $\sigma$ are empirical constants used for curve-fitting of distribution patterns, and they are equal to 2.4 and 0.6 , respectively.

In FDS, water droplet transport is modelled by a Lagrangian approach. The velocity and position of the droplets are calculated from the theory of conservation of momentum. The position and velocity of each droplet are computed from the following equations.

$$
\begin{gathered}
\frac{d}{d t}\left(m v_{p}\right)=m g-\frac{1}{2} \rho C_{d} \pi r^{2}\left(v_{p}-v_{a}\right)\left|v_{p}-v_{a}\right| \\
\frac{d x_{p}}{d t}=v_{p}
\end{gathered}
$$


where the drag coefficient, $C_{d}$, depends on the following function of the Reynolds number $(R e)$ based on the droplet-air relative velocity.

$$
C_{d}=\left\{\begin{array}{cc}
24 / \operatorname{Re} & \operatorname{Re}<1 \\
24\left(0.85+0.15 R e^{0.687}\right) / \operatorname{Re} 1<\operatorname{Re}<1000 \\
0.44 & \operatorname{Re}>1000
\end{array}\right.
$$

The Re of the droplets is defined by

$$
R e=\frac{\rho\left|v_{d}-v_{a}\right| 2 r}{\mu(T)}
$$

where $\mu(T)$ is the dynamic viscosity of air at temperature $T$. Details of these models are available in the FDS technical guide [23]. It is worthy to mention that FDS is well-validated to predict the distribution of flux density when the median droplet size of a spray is known [3].

A computational domain with dimensions of $2 \mathrm{~m} \times 2 \mathrm{~m} \times 2.4 \mathrm{~m}$ was generated to represent the experimental setup. The domain setup of the computational model is shown in Figure 3. The green dots on the floor signify the points where the accumulation rate of water was calculated in the simulation. The floor was divided into 400 compartments, each $10 \mathrm{~cm} \times 10 \mathrm{~cm}$ in the $X Y$ plane so that mass flux distribution could be established similar to the experiment.

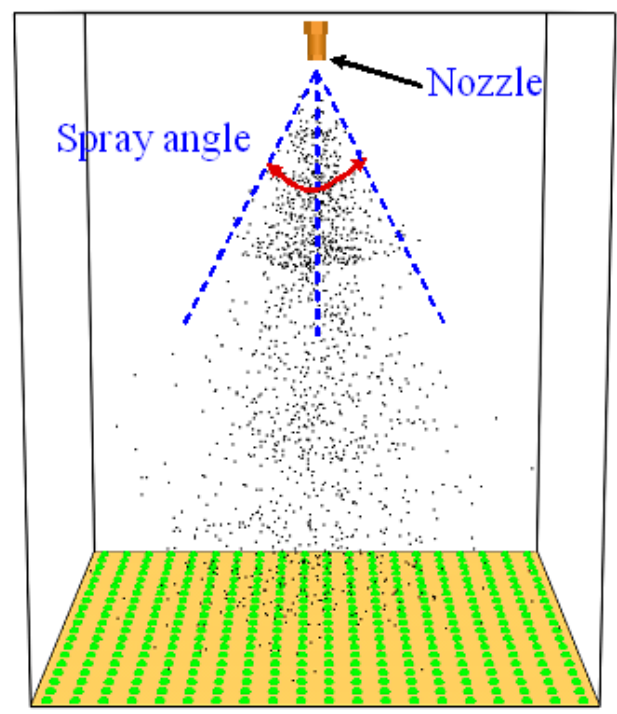

Figure 3. The computational domain of the numerical model.

The numerical outcomes of a model are sensitive to the size of the mesh of the computational domain [24]. As the grid size of a mesh was refined, it was expected that the results would approach that of the continuous governing equations. Therefore, a grid sensitivity analysis was performed to evaluate the convergence of the numerical results. The cubic grid sizes of $10 \mathrm{~cm}, 5 \mathrm{~cm}$ and $2.5 \mathrm{~cm}$ (all same in the $\mathrm{x}, \mathrm{y}$ and $\mathrm{z}$ directions) were tested. The distribution of flux density of the spray for all of the grid sizes was calculated and compared. It was found that the distribution of flux density for $2.5 \mathrm{~cm}$ and $5 \mathrm{~cm}$ cell sizes were almost identical. Therefore, a mesh of $5 \mathrm{~cm}$ cell size was used to discretise the computational domain.

The simulation of water spray was run for an elapsed physical time of $65 \mathrm{~s}$; the nozzle was activated from the beginning of the simulation and terminated after $60 \mathrm{~s}$. The additional $5 \mathrm{~s}$ were used to allow the water drops of the spray to fall down from the nozzle, based on preliminary observations.

The input parameters of the spray were assigned to the CFD model (FDS) for the simulation. The parameters were the median diameter of droplets, water flow rate, angle 
of spray and height of spray. Those parameters (except median diameter of droplets) were quantified in the experiments and used as input variables in the numerical model. The input variables used in the model are presented in Table 1. Median diameters of droplets in the spray were varied as mentioned in the methodology, and the Rosin-Rammler log-normal distribution pattern was used to distribute droplet sizes. The water accumulation rate on the tray was calculated in the numerical model. A flow chart of the numerical analysis for determining of median diameter of droplets is presented in Figure 4. The details of the working steps of domain setup of a numerical model and operation procedures of an FDS model are available in the FDS user's guide [25].

Table 1. The input variables for the numerical model.

\begin{tabular}{lcc}
\hline Parameter & Value & Unit \\
\hline Orifice diameter & 1.524 & $\mathrm{~mm}$ \\
Orientation (azimuthal angle) & 0 & degree \\
Flow pressure $\left(P_{1}\right)$ & 34.5 & bar \\
Flow pressure $\left(P_{2}\right)$ & 75.8 & bar \\
Spray height & 2.3 & $\mathrm{~m}$ \\
Spray angle & 65 & degree \\
Spray pattern type & Solid cone & - \\
\hline
\end{tabular}

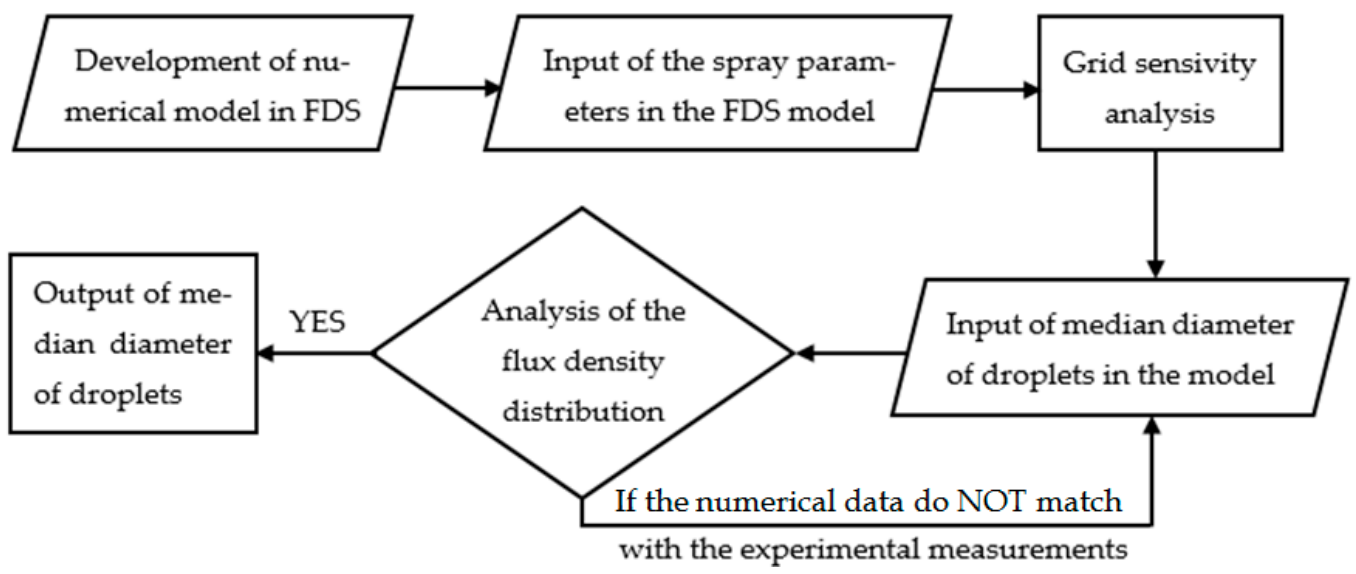

Figure 4. Flow chart of the numerical analysis.

\section{Results and Discussion}

In the first experiment, the flux density distribution of the spray was measured when the operating pressure, $P_{1}$, was 34.5 bar. Then, the numerical simulation was conducted with the droplet sizes of 300, 350, 400 and $500 \mu \mathrm{m}$, and the mass flux density distribution for each droplet size was calculated. The numerical results of the distribution of water spray were compared with that of the experimental data. When the numerical distribution data matched with the experimental data, the corresponding droplet size was taken to be the hypothetical median diameter of the droplets $\left(d m_{1}\right)$ of the spray. A comparison of the numerical value with the experimental data is shown in Figure 5. The hypothetical median size of droplets of the spray in the first experiment was considered as $350 \mu \mathrm{m}$ at 34.5 bar.

As mentioned in the methodology, a second experiment was carried out using a pressure, $P_{2}$, of 75.8 bar, and the spray's corresponding flux density distribution data was measured. Afterwards, the expected $d m_{2}$ of the spray was calculated for $P_{2}$ by using Equation (2). The calculated median diameter of droplets for the spray in the second experiment was $275 \mu \mathrm{m}$. Now, this droplet size and the corresponding pressure were used in the FDS software to generate the spray, and the flux density distribution of water spray was computed in the model. The numerical distribution data of flux density were compared with the experimental data. The results are presented in Figure 6. It was found that the numerical data closely matched the experimental measurement. As a result, it 
appears that the hypothetical median diameter of droplets of 350 and $275 \mu \mathrm{m}$ are the actual median diameter of droplets in the experiments at pressures 34.5 and 75.8 bar, respectively.

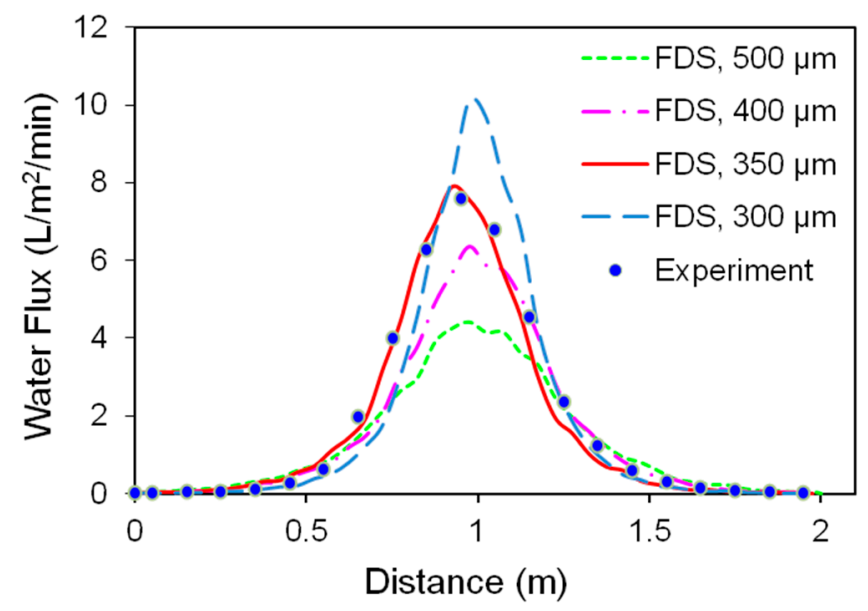

Figure 5. Determination of actual median diameter of droplets by matching the numerical data with the experimental measurement.

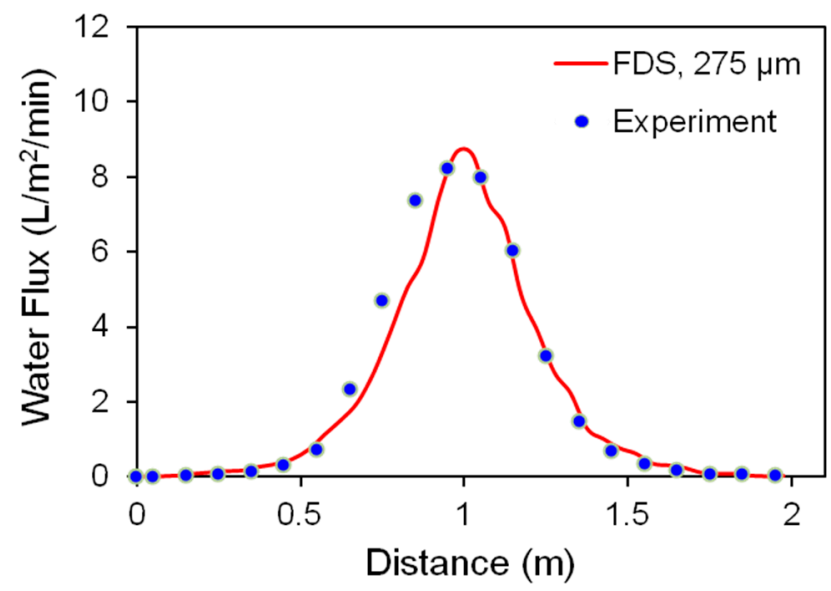

Figure 6. Validation of the calculated median droplet size.

The standard uncertainty analysis of the experimental measurement is discussed here. A statistical analysis has been performed to calculate the uncertainty of measurements based on the least-squares method described in reference [26]. Measurements of the distribution of flux densities produced by the spray have an average experimental uncertainty of $0.103 \mathrm{~L} / \mathrm{m}^{2} / \mathrm{min}$, as also discussed in the previous article of these authors [3]. As a result, the levels of this uncertainty imply that the measured data from the experiments may vary by as much as the equivalent level of uncertainty.

Therefore, the method presented in this paper can be useful to determine the median size of droplets of a water spray. The reasonable accuracy of this method is supported by Whewell's [27] principle of consilience of inductions, which relies on the concordance of evidence from different sources. In this case, evidence converges from both the empirical relationship between the operating pressure and the median diameter of the droplets, and the distribution of simulated mass flux generated by the spray nozzle operating under the hypothesised conditions.

\section{Conclusions}

This paper has suggested a simple technique for determining the median droplet size of a water spray produced by a nozzle. Only two experiments were required in this method to determine the mass flux distribution of water droplets generated by a spray nozzle 
operating at two known pressures along with a reliable numerical model for simulating those experiments. A CFD-based model (FDS) was used by trialling different droplet sizes until the mass flux distribution was matched with the results of the first experiment. The FDS did indeed accurately predict the mass flux distribution when the new pressure and estimated median diameter of the droplets were used as inputs. The result shows that the median droplet size was $350 \mu \mathrm{m}$ at 34.5 bar flow pressure and $275 \mu \mathrm{m}$ at 75.8 bar. Uncertainty analysis of experimental measurements of the flux density distribution of water droplets was performed and discussed in this study. Furthermore, support for the method has been strengthened by invoking Whewell's principle of consilience of inductions [27]. The findings of this research may contribute to establishing a technique in calculating the median diameter of droplets when direct measurement of droplet diameter is not available. Furthermore, the median diameter of the droplet can be used as input parameters in the CFD-based numerical model to simulate the water spray of a nozzle and its interaction with fire. However, further study with direct measurements of droplet sizes is required to provide more confidence in the proposed technique.

Author Contributions: H.M.I.M. developed the model. H.M.I.M., G.T. and K.A.M.M. contributed to conceptualisation, development of the background theory and formulations of the methodology. The text of the paper was formed by H.M.I.M.; K.A.M.M. and G.T. edited the paper and supervised the research direction. All authors have read and agreed to the published version of the manuscript.

Funding: This research received no external funding.

Acknowledgments: The authors wish to acknowledge the technical and financial assistance provided by the Defence Science and Technology Organisation (DSTO), Australia.

Conflicts of Interest: The authors declare no conflict of interest.

\section{References}

1. Santangelo, P.E.; Tartarini, P. Fire Control and Suppression by Water-Mist Systems. Open Thermodyn. J. 2010, 4, 167-184. [CrossRef]

2. Mahmud, H.M.I; Moinuddin, K.A.M.; Thorpe, G.R. Study of water-mist behaviour in hot air induced by a room fire: Model development, validation and verification. Fire Mater. 2016, 40, 190-205. [CrossRef]

3. Mahmud, H.M.I.; Moinuddin, K.A.M.; Thorpe, G.R. Experimental and numerical study of high-pressure water-mist nozzle sprays. Fire Saf. J. 2016, 81, 109-117. [CrossRef]

4. Liu, Z.; Kim, A.K. A review of water mist fire suppression systems- fundamental studies. J. Fire Prot. Eng. 2000, 10, 32-50. [CrossRef]

5. Ren, N.; Baum, H.R.; Marshall, A.W. A comprehensive methodology for characterising sprinkler sprays. Proc. Combust. Inst. 2011, 33, 2547-2554. [CrossRef]

6. Lefebvre, A.H. Atomization and Sprays; Hemisphere: Washington, DC, USA, 1989.

7. Santangelo, P.E. Characterisation of high-pressure water-mist sprays: Experimental analysis of droplet size and dispersion. Exp. Therm. Fluid Sci. 2010, 34, 1353-1366. [CrossRef]

8. Yao, C.; Kalelkar, A.S. Effect of Drop Size on Sprinkler Performance. Fire Technol. 1970, 6, 254-268. [CrossRef]

9. Yu, H.Z.; Symonds, A.P. Sprinkler Drop-Size Measurements, Part I: An Investigation of the FMRC PMS Drop-Size Measuring System; FMRC Technical Report; Factory Mutual Research Corporation: Norwood, MA, USA, 1982; p. 57.

10. Yu, H.-Z. Investigation of Spray Patterns of Selected Sprinklers with the FMRC Drop Size Measuring System. Fire Saf. Sci. 1986, 1, 1165-1176. [CrossRef]

11. Chan, T.S. Measurements of Water Density and Drop Size Distributions of Selected ESFR Sprinklers. J. Fire Prot. Eng. 1994, 6, 79-87. [CrossRef]

12. Montero, J.; Tarjuelo, J.M.; Carrión, P. Sprinkler droplet size distribution measured with an optical spectropluviometer. Irrig. Sci. 2003, 22, 47-56. [CrossRef]

13. Dwomoh, F.A.; Yuan, S.; Li, H.; Zhu, X.; Liu, J.; Mensah, R.; Fordjour, A. Analysis of Water Droplet Distribution in Wind for the Fluidic Sprinkler. Water 2020, 12, 3320. [CrossRef]

14. Wang, X.S.; Chow, W.K.; Wu, M. A review on determining water spray droplet characteristics by laser techniques. J. Appl. Fire Sci. 2008, 18, 211-239. [CrossRef]

15. Plumecocq, W.; Audouin, L.; Joret, J.P.; Pretrel, H. Numerical method for determining water droplets size distributions of spray nozzles using a two-zone model. Nucl. Eng. Des. 2017, 324, 67-77. [CrossRef]

16. Sikanen, T.; Vaari, J.; Hostikka, S.; Paajanen, A. Modeling and Simulation of High Pressure Water Mist Systems. Fire Technol. 2014, 50, 483-504. [CrossRef] 
17. Kim, S.C.; Ryou, H.S. An experimental and numerical study on fire suppression using a water-mist in an enclosure. Build. Environ. 2003, 38, 1309-13016. [CrossRef]

18. Yao, B.; Cong, B.H.; Qin, J.; Chow, W.K. Experimental study of suppressing Poly (methyl methacrylate) fires using water mists. Fire Saf. J. 2012, 47, 32-39. [CrossRef]

19. Jenft, A.; Collin, A.; Boulet, P.; Pianet, G.; Breton, A.; Muller, A. Experimental and numerical study of pool fire suppression using water mist. Fire Saf. J. 2014, 67, 1-12. [CrossRef]

20. Liu, Y.; Jiang, Z.; Wang, D.; Li, X. Experimental research on the water mist fire suppression performance in an enclosed space by changing the characteristics of nozzles. Exp. Therm. Fluid Sci. 2014, 52, 174-181. [CrossRef]

21. Ura, F.; Kawabata, N.; Tanaka, F. Characteristics of smoke extraction by natural ventilation during a fire in a shallow urban road tunnel with roof openings. Fire Saf. J. 2014, 67, 96-106. [CrossRef]

22. Fleming, R.P. Automatic Sprinkler System Calculations. In The SFPE Handbook of Fire Protection Engineering, 4th ed.; DiNenno, P.J., Ed.; National Fire Protection Association: Quincy, MA, USA, 2008; pp. 4-86.

23. McGrattan, K.; Hostikka, S.; Floyd, J.; McDermott, R.; Vanella, M. Fire Dynamics Simulator (Version 6), Technical Reference Guide, Volume 1: Mathematical Model, NIST Special Publication 1018-1, 6th ed.; Revision: FDS6.7.7-0-gfe0d4ef38; National Institute of Standards and Technology (NIST); U.S. Department of Commerce: Gaithersburg, MA, USA, 2021. [CrossRef]

24. Moinuddin, K.A.M.; Sutherland, D.; Mell, R. Simulation study of grass fire using a physics-based model: Striving towards numerical rigour and the effect of grass height on the rate-of-spread. Int. J. Wildland Fire 2018, 27, 800-814. [CrossRef]

25. McGrattan, K.; Hostikka, S.; Floyd, J.; McDermott, R.; Vanella, M. Fire Dynamics Simulator (Version 6), User's Guide, NIST Special Publication 1019, 6th ed.; Revision: FDS6.7.7-0-gfe0d4ef38; National Institute of Standards and Technology (NIST); U.S. Department of Commerce: Gaithersburg, MA, USA, 2021. [CrossRef]

26. Taylor, B.N.; Kuyatt, C.E. Guidelines for Evaluating and Expressing the Uncertainty of NIST Measurement Results; NIST Technical Note 1297; National Institute of Standards and Technology (NIST): Gaithersburg, MA, USA, 1994.

27. Whewell, W. The Philosophy of the Inductive Sciences-Founded Upon Their History; John, W., Ed.; Parker Publication: London, UK, 1840 . 